\title{
Anti-A haemagglutinins in factor VIII concentrates
}

\author{
JK SMITH,* PJ BOWELL, $†$ E BIDWELL,* AND HH GUNSON† \\ From the *Plasma Fractionation Laboratory, Oxford, and the †Regional Transfusion Centre, Oxford, UK
}

SUMMARY Experimental evidence has been obtained that cryoprecipitation concentrates anti-A in mixtures of group $\mathrm{O}$ and group $\mathrm{A}$ plasma by a mechanism that does not operate in group $\mathrm{O}$ plasma alone. It has been concluded that the anti-A/A polysaccharide complex is less soluble during cryoprecipitation than anti-A immunoglobulin, and this complex dissociates to give free anti-A when the cryoprecipitate is redissolved. From a practical point of view, factor VIII concentrates prepared from cryoprecipitate obtained from single donations of plasma unselected for ABO group contain significantly less anti-A than those prepared from mixing pools of plasma in which partial neutralisation of anti-A has occurred before cryoprecipitation.

All factor VIII preparations contain anti-A and anti-B, but correlation between the concentrations of these antibodies and development of haemolysis in haemophiliacs undergoing intensive therapy has not been demonstrated. ${ }^{1}$ Despite this, it seems prudent to prepare factor VIII concentrates containing as low a level of anti-A and anti-B as is practical. There are several factors which determine the $A$ and $B$ antibody concentration in factor VIII preparations, notably the starting level, largely dependent on the proportion of group $\mathbf{O}$ to group A donations present, the quantity of plasma trapped in the cryoprecipitate, and the degree of neutralisation effected by the presence of $A$ and $B$ polysaccharides. It may be influenced also by the method of purification of the factor VIII.

In England, source plasma for factor VIII concentrates has been prepared in 5-litre packs by pooling and freezing 24 to 30 donations of plasma unselected for ABO group;2 20-120 5-litre packs yield bulk cryoprecipitate for further fractionation. A proposal to use frozen single donations of plasma as the starting material led to speculation that the levels of anti-A and anti-B in the resulting factor VIII preparations would be increased, since there would be no opportunity for neutralisation to take place before collection of the cryoprecipitate. This possibility was investigated in small-scale experiments and by fractionating 100 -litre pools of plasma frozen as single donations or in 5-litre packs.

\section{Material and methods}

Blood donations were collected into Fenwal packs and

Received for publication 28 February 1980
$180-200 \mathrm{ml}$ plasma was separated within 18 hours. The plasma was either retained in the transfer pack as a single donation and frozen to $-30^{\circ} \mathrm{C}$ within 30 minutes or pooled into 5-litre packs. Usually each pool comprised 24 donations. Pooling was performed at $18^{\circ}-20^{\circ} \mathrm{C}$ over about 30 minutes, and the 5-litre pool was frozen in a plate freezer for 100 minutes. $^{2}$ For some experiments the 5-litre packs were filled with plasma from group $\mathrm{O}$ or group $\mathrm{A}$ donors only. Plasma was stored at $-30^{\circ} \mathrm{C}$ to $-40^{\circ} \mathrm{C}$ for several weeks before fractionation.

Assay of anti-A was carried out according to the method described by Bowell et al..$^{3}$ All samples for assay were frozen within a few minutes of completing the relevant part of the experiment and thawed at $37^{\circ} \mathrm{C}$ immediately before anti-A assay. The delay between the sample thawing and the haemagglutination reaction was approximately 15 minutes. The anti-A concentration in any plasma or reaction mixture did not change significantly when assayed after a second freezing and thawing.

Factor VIII concentrates were prepared from the cryoprecipitate derived from approximately $100 \mathrm{~kg}$ pools of plasma extracted at $20^{\circ}-25^{\circ} \mathrm{C}$ with tris buffer and partially purified by adsorption with aluminium hydroxide and cold precipitation before filtration and freeze drying. 4

Factor VIII assays were performed by the method described by Smith et al. ${ }^{4}$

Cryoprecipitates were prepared from small pools comprising six single donations of group A plasma, from six group $O$ donations selected for higher than average levels of anti-A, and from mixtures of equal volumes of each type of plasma. These pools were frozen in stainless steel beakers, and cryoprecipitates were obtained by manual thawing in a water bath 
at $20^{\circ} \mathrm{C}$ to a final temperature of not greater than $2{ }^{\circ} \mathrm{C}$, centrifugation and redissolving the precipitate in a volume of citrate-saline solution equivalent to $5 \%$ of the original plasma volume.

Anti-A assays were carried out also on factor VIII concentrates made by several commercial firms.

\section{Results}

SMALL-SCALE EXPERIMENT (Table 1)

An experiment using small group-segregated pools of plasma was designed to emphasise some quantitative effects and to simulate the first stages of preparation of factor VIII concentrates from 5-litre pools of plasma (section 1) or from single donations of plasma (sections 2 and 3). All assays of anti-A were carried out on coded samples, the origin of which was unknown to the operator.

\section{Section 1}

Aliquots of group $\mathrm{O}$ and group A plasma were mixed and either frozen immediately or allowed to stand at $20^{\circ} \mathrm{C}$ for two hours before freezing. Anti-A was assayed in the original group $\mathbf{O}$ and group $\mathbf{A}$ pools, in the mixture of group $\mathbf{O}$ and group A plasma, and in the cryoprecipitate derived from the mixed plasma and the cryosupernatant. The redissolved cryoprecipitate derived from the mixed plasma had a higher concentration of anti-A than that of the corresponding cryosupernatant. Thirty-eight per cent of the original anti-A content was neutralised immediately, and only a further $13 \%$ after 2 hours' incubation at $20^{\circ} \mathrm{C}$.

\section{Sections 2 and 3}

Group $\mathbf{O}$ and group A cryoprecipitates were mixed at the cryosuspension stage, that is, after thawing to $2^{\circ} \mathrm{C}$ but before centrifugation (section 2 ) or after resolution of the centrifuged cryoprecipitate (section 3 ). Both these procedures gave similar results, and it is clear that there was a significant reduction in the anti-A content in cryoprecipitates prepared in this manner compared with those derived from pools of group $\mathbf{O}$ and group $\mathbf{A}$ plasmas. Also, it was evident that the anti-A in cryoprecipitate derived from group O plasma (section 3(a)) is lower in concentration than that from mixtures of $\mathbf{O}$ and $\mathbf{A}$ plasma (section 1(a) and $(b)$ ).

\section{LARGE-SCALE FRACTIONATION (Table 2)}

Similar results were obtained when the above experiments were scaled up to the fractionation of approximately $100 \mathrm{~kg}$ pools. Thus, when cryoprecipitate or factor VIII concentrate was derived from mixing 5-litre pools of plasma containing an equal number of group $\mathbf{O}$ and group $\mathbf{A}$ donations, there was a significantly higher concentration of anti-A compared with the antibody concentrations found when the mixing took place at the cryosuspension or cryoprecipitate stages.

Since individual batches may vary with respect to their factor VIII content it is important to correlate

Table 1 Anti-A content* of cryoprecipitates from plasmas of segregated or mixed $O$ and A groups

\begin{tabular}{|c|c|c|c|c|c|c|c|c|}
\hline \multicolumn{3}{|l|}{ Section 1} & \multicolumn{3}{|l|}{ Section 2} & \multicolumn{3}{|l|}{ Section 3} \\
\hline \multirow[t]{2}{*}{ Preparation tested } & \multicolumn{2}{|c|}{ Anti-A concentration } & \multirow[t]{2}{*}{ Preparation tested } & \multicolumn{2}{|c|}{ Anti-A concentration } & \multirow[t]{2}{*}{ Preparation tested } & \multicolumn{2}{|c|}{ Anti-A concentration } \\
\hline & Units/ml & $\begin{array}{l}\text { Units \% } \\
\text { theoretical }\end{array}$ & & Units/ml & $\begin{array}{l}\text { Units } \% \\
\text { theoretical }\end{array}$ & & Units/ml & $\begin{array}{l}\text { Units } \% \\
\text { theoretical }\end{array}$ \\
\hline \multirow[t]{2}{*}{$\begin{array}{l}\text { A plasma } \\
\text { O plasma }\end{array}$} & $\begin{array}{r}0 \\
429\end{array}$ & & \multirow{4}{*}{$\begin{array}{l}\text { (a) Mixture of } \\
\text { O and A } \\
\text { cryosuspensions } \\
\text { Cryoprecipitate } \\
\text { of }(a)\end{array}$} & & & \multirow{8}{*}{$\begin{array}{l}\text { O cryoprecipitate } \\
\text { O cryosupernatant } \\
\text { (a) Mixture of } \\
\text { O and A } \\
\text { cryoprecipitates } \\
\text { Mixture of } \\
\text { O and A } \\
\text { cryosupernatants }\end{array}$} & & \\
\hline & & & & & & & $\begin{array}{l}116 \\
406\end{array}$ & $\begin{array}{r}1 \cdot 15 \\
94 \cdot 60\end{array}$ \\
\hline \multirow{2}{*}{$\begin{array}{l}\text { (a) Mixed }(\mathrm{O}+\mathrm{A}) \\
\text { plasma frozen } \\
\text { immediately } \\
\text { Cryoprecipitate } \\
\text { of }(a)\end{array}$} & 133 & $62 \cdot 0$ & & 130 & $60 \cdot 60$ & & & \\
\hline & 195 & $3 \cdot 77$ & & 32 & 0.63 & & 37 & $0 \cdot 73$ \\
\hline $\begin{array}{l}\text { Cryosupernatant } \\
\text { of }(a)\end{array}$ & 94 & $43 \cdot 80$ & $\begin{array}{l}\text { Cryosupernatant } \\
\text { of }(a)\end{array}$ & 130 & $60 \cdot 60$ & & 132 & $61 \cdot 50$ \\
\hline \multirow{3}{*}{$\begin{array}{l}\text { (b) Mixed }(\mathrm{O}+\mathrm{A}) \\
\text { plasma frozen } \\
\text { after } 2 \mathrm{~h} 20^{\circ} \mathrm{C} \\
\text { Cryoprecipitate } \\
\text { of }(b) \\
\text { Cryosupernatant } \\
\text { of }(b)\end{array}$} & 105 & $49 \cdot 0$ & & & & & & \\
\hline & 192 & $3 \cdot 76$ & & & & & & \\
\hline & 87 & $40 \cdot 60$ & & & & & & \\
\hline
\end{tabular}

* To allow for the effect of volume difference the total anti-A content of each solution was expressed as a percentage of the anti-A calculated to be present in the appropriate starting plasma. 
Table 2 Anti-A in factor VIII concentrates from different sources

\begin{tabular}{lll}
\hline $\begin{array}{l}\text { Source of factor VIII } \\
\text { concentrate }\end{array}$ & $\begin{array}{l}\text { No. of batches } \\
\text { tested }\end{array}$ & $\begin{array}{l}\text { Ratio anti-A }(\mathrm{U} / \mathrm{ml}) \\
\text { to factor VIII activity } \\
(I U / \mathrm{ml})\end{array}$ \\
\hline $\begin{array}{l}\text { 5-litre pools (each of } \\
\text { 24 random donations) }\end{array}$ & 23 & \\
Single random & & $23 \cdot 7$ (SD 4.1) \\
donations & 23 & $5 \cdot 1(\mathrm{SD} 1 \cdot 1)$ \\
Commercial & & \\
preparations & & $5 \cdot 9$ \\
A & 4 & $15 \cdot 5$ \\
B & 3 & $12 \cdot 5$ \\
C & 3 & $10 \cdot 7$ \\
D & 1 & $3 \cdot 6$ \\
E & 1 & \\
\hline
\end{tabular}

the anti-A levels in the factor VIII concentrates with their specific activity. Table 2 shows the ratio of anti-A to factor VIII activity in concentrates derived from large-scale fractionation of 5-litre pools of plasma compared with those prepared from single plasma donations pooled at the cryosuspension stage of fractionation. In each case the donations were unselected for ABO group. There is almost a fivefold difference in these ratios, confirming that the results obtained in the pilot experiments are reflected in larger scale manufacture.

Also included in Table 2 are similar ratios for some batches of imported commercial factor VIII available in the United Kingdom. All of these batches had a lower ratio of anti-A to factor VIII activity than the material prepared from 5-litre pools, and two products showed ratios similar to those found in concentrates obtained from single plasma donations.

\section{Discussion}

The experiments described in this paper gave interesting and unexpected results. Using randomly selected plasma for cryoprecipitation, it could be argued that the anti-A content in the cryoprecipitate was merely a reflection of the concentration of anti-A of the cryosupernatant trapped in the precipitate, which accounts for up to $80 \%$ of the cryoprecipitate weight. However, when equal volumes of group $\mathbf{O}$ and group A plasma were mixed at $20^{\circ} \mathrm{C}$, the resulting cryoprecipitate contained a higher concentration of anti-A than its cryosupernatant and also a higher concentration than that of the cryoprecipitate made from group $\mathbf{O}$ plasma alone. This indicates that cryoprecipitation concentrates anti-A by a mechanism that does not operate in group $\mathrm{O}$ plasma alone.

There was clear evidence that neutralisation of anti-A occurred rapidly when group $O$ and group $A$ plasmas were mixed. It was concluded that the complex between anti-A and $\mathrm{A}$ polysaccharide is less soluble under processing conditions used for cryoprecipitation than anti-A alone, and this complex dissociates to give free anti-A when the cryoprecipitate is dissolved at $20^{\circ} \mathrm{C}$. This observation may have important implications for other antigenantibody aggregates; for example, the inclusion of $\mathrm{HB}_{\text {s }}$ antibody-positive donations in plasma pools intended for factor VIII production might alter, unpredictably, the proportions of antigen and antibody in the cryoprecipitate.

From a practical point of view the preparation of factor VIII concentrates of intermediate specific activity from cryosuspensions and cryoprecipitates obtained from single donations of plasma contain significantly less anti-A than those prepared from mixing pools of plasma. Also, in this study, we have considered only the effect on anti-A concentrations. There is no reason to suppose that anti-B would not behave in a similar manner during cryoprecipitation.

The commercial preparations examined have differing ratios of anti-A to factor VIII activity. A low ratio might be accounted for by a preponderance of group A plasma in the pools for fractionation, exploiting the high plasma factor VIII concentration associated with this blood group $;^{5}$ commercial fractionators usually use single-donor units of plasma obtained by plasmapheresis. Unpublished experiments suggest also that further purification of concentrates, for example, by precipitation with polyethylene glycol, may further reduce the ratio of anti-A to factor VIII.

Use of single donations of plasma for factor VIII production appears to reduce anti-A to the lowest level consistent with processing from plasma donations of unselected $\mathrm{ABO}$ group. If it can be shown clinically that lower levels still are of benefit to the haemophiliac then some form of immunoadsorption may have to be considered since segregation of every plasma pool by ABO group poses several problems. Insoluble reagents carrying synthetic blood group sites, available for laboratory use, have been shown to adsorb anti-A from the intermediate factor VIII concentrates (JKS and EB, personal observation). Extensive testing would be required before concentrates prepared using such reagents could be offered for clinical use.

\section{References}

${ }^{1}$ Seeler RA. Unsolved therapeutic problems in haemophilia. Proceedings of a conference sponsored by the Bureau of Biologics, Bethesda, Maryland. DHEW Publication Number (NIH) 77-1089, 1976:113-9.

2 Vallet L. Freezing plasma in 5-litre bags for storage and thawing for use. Vox Sang 1973;24:550-9.

${ }^{3}$ Bowell P, Abdalla S, Snape TJ, Gunson HH. Evaluation of an Auto-Analyzer method for quantitating anti-A and anti-B haemagglutinins in factor VIII preparations. $J$ 
Clin Pathol 1980; 33:598-692

${ }^{4}$ Smith JK, Evans DR, Stone V, Snape TJ. A Factor VIII concentrate of intermediate purity and higher potency. Transfusion 1979;19:299-306.

5 Preston AE, Barr A. The plasma concentration of Factor VIII in the normal population. II. The effects of age, sex and blood group. Br J Haematol 1964;10:238-45.

Requests for reprints to: Dr JK Smith, Plasma Fractionation Laboratory, Churchill Hospital, Oxford OX3 7LJ, UK. 